\title{
IDENTIFICAÇÃO DE MICRONÚCLEOS EM CÉLULAS EPITELIAIS DA MUCOSA JUGAL DE PACIENTES ONCOLÓGICOS
}

\author{
AUTOR: TATIANA FRAGA FONSECA \\ CO-AUTOR/ORIENTADOR: HAYANA RAMOS LIMA
}

Resumo: O câncer é uma das doenças não transmissíveis mais prevalentes no mundo cujos impactos na qualidade de vida e implicações socioeconômicas afetam diversos países em desenvolvimento. $\mathrm{O}$ tratamento oncológico pode incluir diferentes modalidades terapêuticas, como quimioterapia (QT), radioterapia e/ou cirurgia. Todas essas condutas estão associadas a diferentes graus de complicações. No tratamento quimioterápico, a mucosite oral (MO) figura-se como uma das condições que frequentemente afeta pacientes sob tratamento oncológico. Estas lesões se iniciam por dano ao material genético das células e podem evoluir para ulcerações, impossibilitando a alimentação do paciente, e até suspensão temporária do tratamento antineoplásico. A identificação dos micronúcleos é realizada por meio de citologia e consiste em uma técnica de baixo custo e fácil execução. Esta pesquisa prevê a coleta da amostra de aproximadamente 50 pacientes sob tratamento quimioterápico na UNACON de Teixeira de Freitas. Além do grupo controle composto por 15 indivíduos saudáveis pareados quanto ao gênero e idade em relação ao grupo de pacientes, recrutados da comunidade acadêmica da Universidade Federal do Sul da Bahia (campus Paulo Freire). As amostras de células epiteliais são obtidas através de raspagem gentil da mucosa oral e coradas com periódico de Schiff e Fast green. A identificação de micronúcleos será registrada em relação à frequência desses eventos por 2.000 células de cada paciente.

Palavras-chave: Citotoxicidade, Quimioterapia, Mucosite. 